\title{
RETRATO DO LINGUISTA QUANDO JOVEM
}

Eliane Silveira*

(iD) https://orcid.org/0000-0002-4862-4547

Como citar este artigo: SILVEIRA, E. Retrato do linguista quando jovem. Todas as Letras - Revista de Língua e Literatura, São Paulo, v. 22, n. 2, p. 1-11, maio/ago. 2020. DOI 10.5935/1980-6914/eLETDO2013488

Submissão: junho de 2020. Aceite: julho de 2020.

Resumo: Este artigo traz uma reflexão sobre a formação do linguista a partir de observações de Saussure no seu manuscrito conhecido como Souvenirs, de 1903. A partir das suas lembranças da infância e da juventude, o linguista genebrino retoma elementos significativos da sua formação. Neste artigo priorizamos alguns dos aspectos do endereçamento dessas lembranças a um colega, o linguista alemão Wilhelm Streitberg, e discutimos o seu estatuto na formação do linguista.

Palavras-chave: Ferdinand de Saussure. Linguista. Manuscrito. Lembranças. Linguistica. 


\section{INTRODUÇÃO}

$\boldsymbol{O}$ título deste artigo é uma analogia ao título da obra de James Joyce, Retrato do artista quando jovem, escrito em Dublin, no início do século $\mathrm{XX}$, composição própria de um gênero que se conhece como romance de formação, ou bildungsroman. Aqui trataremos do manuscrito de Ferdinand de Saussure Récit autobiographique de sa jeunesse et de ses études ${ }^{1}$, escrito à mesma época, em Genebra, onde o linguista retrata um aspecto do seu percurso nos estudos da linguagem. A analogia anunciada no título tem alguns pontos de ancoragem, apesar de os textos serem incomparáveis, e não é o objetivo do artigo cotejá-los. A modesta leitura do primeiro pode, num certo momento, inspirar uma certa leitura do segundo, e isso não nos parece pouco quando se trata de um manuscrito tão delicado quanto esse que nos propomos trabalhar agora.

Joyce publica, em 1914, o romance de formação em questão, Saussure escreve, em 1903, e nunca publica, o texto chamado Souvenirs, em Genebra, que retrata a sua formação em linguística. Os dois, em estilos muito diferentes, tratam da formação de um rapaz cujos interesses, na infância e juventude, são os pilares da sua constituição. O leitor experiente e que conhece o trabalho desses dois autores, cânones da área de Letras e Linguística, sabe que um se permite caminhar com todo o seu vigor pela vereda da ficção e outro é reconhecido por fundar uma ciência e, assim, o seu escrito buscará o retrato mais fiel que as suas lembranças puderem lhe fornecer. Cada um, evidentemente, será traído pela sua própria escrita a sua maneira, já que o campo da linguagem nos dá constantemente elementos para discutir os limites entre a ficção e a realidade. Sem nos estender nessa questão espinhosa que por si tomaria todo o presente artigo, o mínimo que se pode dizer a esse respeito é que o ato de rememorar traz em si a possibilidade de uma construção e também é preciso dizer que muito já foi discutido sobre os desdobramentos biográficos na ficção, especialmente quando se trata de um romance de formação. A respeito do romance de Joyce, Aubert (1993, p. 40) sustenta que se trata mesmo de uma obra biográfica. Segundo ele, são tantos os eventos e menções a lugares que podem ser historicamente apurados "a tal ponto que biógrafos e críticos estão constantemente ameaçados de escorregar da ordem da ficção para os fatos". Ainda assim, talvez fosse prudente não descuidar da grande distância que separa os dois autores que, aparentemente, não eram da mesma larva linguageira, apesar de os dois serem escritores persistentes e consistentes nos seus estilos e propósitos.

Esses poucos pontos de ancoragem entre os dois escritos nos instigam a situar um aspecto pouco discutido do manuscrito de Saussure: a formação do linguista. O seu manuscrito tem o objetivo específico de explicar a origem das reflexões que sustentaram o seu trabalho final de formação em Leipzig. Contudo, ao percorrê-lo é possivel perceber que as informações e impressões do genebrino sobre a sua formação têm a potência de nos fazer refletir a respeito de singularidades da formação de um linguista e, assim, nos permitem ir além da questão específica proposta pelo próprio Saussure no Souvenirs.

Sigmund Freud e Jean Claude-Milner orientam nossa empreitada. O texto do primeiro, Leonardo da Vinci e uma lembrança de sua infância, publicado em Vie-

1 Esse documento é mais conhecido como Souvenirs, como será referido nesta reflexão. 
na, em 1910, e, do segundo, o livro O amor da lingua, resultado de uma série de conferências do autor anunciadas em 1974, em Paris. Freud tem a vantagem de, ao nos trazer Leonardo da Vinci, abranger tanto o artista quanto o cientista, o que ele já indica no início do seu texto: "O pesquisador que nele existia nunca libertou totalmente o artista durante todo o curso de seu desenvolvimento". Além disso, a tematização das memórias de infância de Leonardo nos inspira a tocar nas memórias de infância trazidas por Saussure. Já em O amor da língua, o autor levanta explicitamente a possibilidade de Saussure não só ter legado os fundamentos de uma ciência, mas também, nas suas palavras, "[...] um modo de ser que era, até então, inédito". Essa indicação de Milner foi fundamentada nos efeitos da produção de Saussure sobre uma extensa área de saber e nós ousamos transportá-la para a questão que fundamenta esta discussão, sobre a formação do linguista, a partir de um manuscrito, Souvenirs, que não foi objeto de análise de Milner.

É sabido que o corpus saussuriano é imenso e diversificado. Cobre quase meio século com uma produção caudalosa e potente. Tais características que combinam amplidão e profundidade certamente se revelam um sedutor convite à pesquisa, mas também uma rigorosa imposição de limites à ambição do pesquisador em função da extensão da trava. Assim, certamente que a questão sobre a formação do linguista pode ser recolhida em mais de uma das inúmeras fontes saussurianas, evidentemente em vários dos manuscritos nos quais o genebrino se propõe a tratar da natureza da lingua, mas destacamos também a sua epistolografia, suas publicações em vida e o Curso de Linguística Geral. Fontes muito diversas entre si podem nos trazer, igualmente, dados para essa questão.

Justamente por isso, um dos primeiros cuidados metodológicos do pesquisador da fortuna saussureana diz respeito ao recorte do corpus. Sabemos que Saussure raramente abandona uma questão. Mesmo com o passar do tempo ou a mudança de tema, muitos pontos se transformam no decorrer de sua elaboração e de acordo com o tema escolhido, mas estão presentes em variados materiais de épocas distintas. O manuscrito que escolhemos trabalhar em função da questão da formação do linguista, Souvenirs, é por si só um material que ocuparia bem mais de um artigo para ser explorado e com conteúdo totalmente apropriado para essa discussão. Então comecemos por apresentá-lo detalhadamente ao leitor brasileiro, cuja intimidade com esse material ainda é pequena.

\section{O MANUSCRITO}

O manuscrito Souvenirs (ms-fr 3957-1), como já dissemos, foi escrito em 1903, ocupa um caderno pequeno totalizando 20 folhas escritas, não em sequência e nem totalmente preenchido. Ficou conhecido na década de 1950 e está arquivado na Biblioteca Pública de Genebra desde então. Quando ele lá chegou, foi catalogado por Robert Godel, que, em função da sua importância histórica e teórica, se propôs a transcrevê-lo e publicá-lo, o que aconteceu por meio da revista Cahiers Ferdinand de Saussure, em 1960, editada pela Livraria Droz. Não há ainda uma tradução desse manuscrito em português e ele, de fato, é muito citado nos meios exclusivos de pesquisa da fortuna saussureana, mas não muito trabalhado.

A ausência de muitos trabalhos aprofundados sobre o Souvenirs talvez se explique por duas características importantes dele e que caracterizam o seu 
tema central. O seu conteúdo gira, fundamentalmente, em torno do Mémoire sur le système primitif des les voyelles dans les langues indo-européennes ${ }^{2}$, publicado em 1879, que por sua vez implica dois pontos importantes que estão em questão no manuscrito, a saber, os estudos do grego antigo e também a melindrosa discussão sobre a questão do plágio. O primeiro é de grandes dificuldades para o linguista do século XXI, em geral, em função do parco conhecimento das línguas antigas e suas questões teóricas, apenas o especialista em grego antigo sentiria-se à vontade diante de tal tema. O segundo supõe dificuldades diferentes, incluindo uma questão delicada para qualquer autor de uma área academicamente consolidada, especialmente quando envolve um autor da monta de Saussure. Talvez por isso o manuscrito seja pouco trabalhado, embora seja muito interessante dos pontos de vista histórico e teórico ${ }^{3}$.

Além disso, o próprio Mémoire, único livro publicado por Saussure em vida e tema do Souvenirs, não teve o merecido destino, como lembra a estudiosa deste trabalho do genebrino, Marie-José Béguelin (2003, p. 151-152):

A história das ciências oferece situações paradoxais. O Mémoire, lugar de ruptura epistemológica, ao mesmo tempo síntese e deslocamento do saber linguístico de seu tempo, levado a cabo pelo jovem Saussure com um talento quase mozartiano, foi lentamente, mas com certeza, ofuscado durante o século XX pelo Curso de Linguística Geral, publicado em 1916.

Para além da sombra que o Curso de Linguistica Geral tenha feito, e certamente fez, no Mémoire, é preciso lembrar que na história do genebrino, de genialidade reconhecida mundialmente há mais de um século, se cruzam o sucesso e o fracasso das suas obras. Tanto um quanto outro, o triunfo e o infortúnio, podem incidir sobre a mesma obra, Mémoire ou CLG, em tempos ou lugares de interpretação diferentes. Talvez seja isso, afinal, que faça com que Saussure seja considerado um autor clássico. O manuscrito que trazemos para esta reflexão pode, de certa forma, trazer elementos que joguem luz sobre a posição do próprio Saussure a respeito das polêmicas que sustentam recepções tão diversas da sua produção, especialmente esta que ele experienciou com a única publicação de um livro autoral em vida.

Contudo, devido à complexidade do manuscrito, dirigiremos a nossa atenção a um foco específico da exposição de Saussure. Trata-se do lugar que o seu interlocutor ocupa no relato do seu percurso de formação como linguista. Ele escolhe Wilhelm Streitberg, um indo-europeísta, mais especificamente germanista, que à época da escrita desse manuscrito era professor na Universidade de Munique, na Alemanha, e no passado havia sido seu colega. Destacaremos, para efeito desta breve reflexão, dois aspectos relacionados à interlocução: a horizontalidade da relação e a cumplicidade teórica. Tal perspectiva nos permitirá içar da escrita saussureana momentos de rememoração muito particulares e bastante laterais nas discussões, também raras, sobre a formação do linguista.

\section{A horizontalidade Da RELAÇÃo}

Saussure anuncia esse manuscrito, datado de 14 de março de 1903, a Streitberg: "Je vous enverrai très prochainement le petit mémoire rétrospectif que vous acceptez, 
avec tant d'obligeance, de garder, pour usage éventuel"4 (VILLANI, 1990, p. 25). Esta carta responde a uma outra de Streitberg, do mês anterior, e é por isso que, ao redigir o seu texto, ele credita ao linguista alemão a inspiração de tais reflexões:

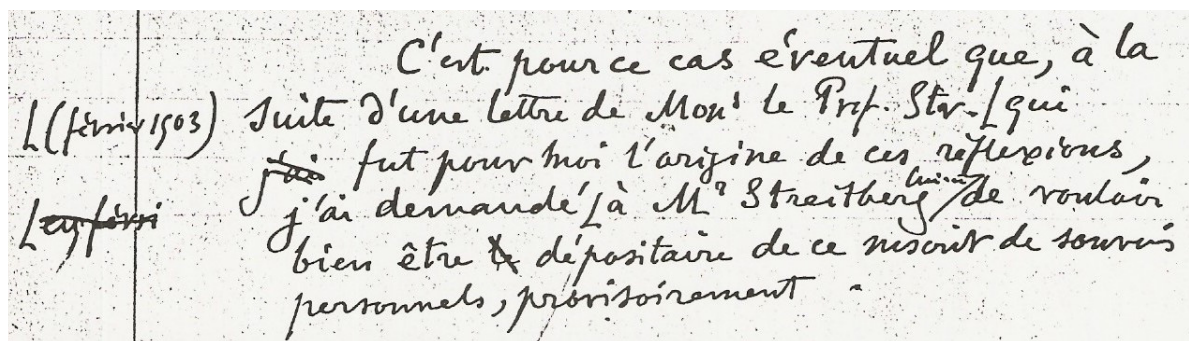

É para esse caso eventual ${ }^{5}$ que, em sequência a uma carta do professor Streitberg (fevereiro 1903) que eu tenho foi para mim origem destas reflexões, eu pedi em fev ao próprio sr. Streitberg ele mesmo de me fazer o favor de ser a depositário deste manuscrito de lembranças pessoais, provisoriamente (folha 3).

Wilhelm Streitberg (1864-1925), mais jovem que o genebrino e chamado por ele de "colega" em diversas cartas, parece ter desfrutado de uma convivência amigável com Saussure e certamente circularam pelos mesmos meios acadêmicos da Alemanha. Dessa forma, o alemão, enquanto indo-europeísta e com formação muito parecida com a do suíço, também se deteve em pontos teóricos tratados no Mémoire e, ademais, reconheceu neste a autenticidade das reflexões de Saussure, com quem ainda mantinha contato, mais de duas décadas depois da sua publicação. Assim, Saussure escolhe anunciar essa escrita a um interlocutor constituído na horizontalidade das suas relações e também é a ele que pretende confiar tal relato:

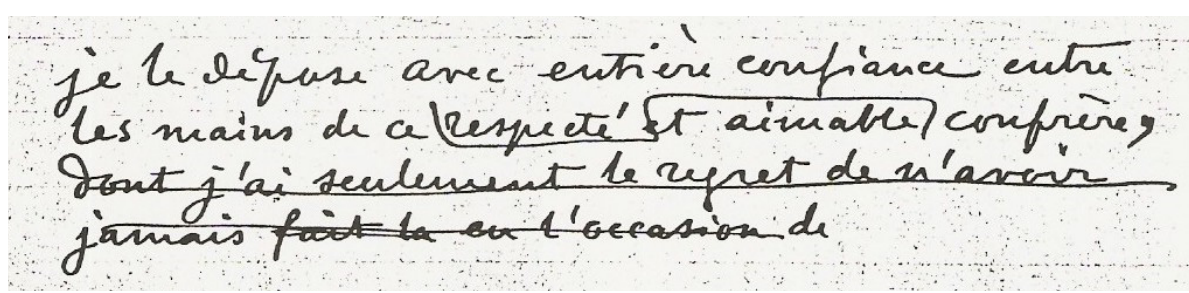

Eu o deposito com inteira confiança entre as mãos deste respeitável e amável camarada; o que só me arrependo de nunca ter feito por ocasião de (folha 4).

A declaração de confiança de Saussure traz, em seguida, sob as rasuras, um arrependimento de já não ter feito esse relato antes. Mas ele se detém e não segue a sua exposição pela linha do que em português é contemplado, exemplarmente, pelo futuro do pretérito, aquilo que poderia ter sido ${ }^{6}$.

4 Essa carta de Saussure encontra-se arquivada em Leipzig e foi transcrita e publicada por P. Villani em 1990, no conjunto de textos denominados "Documenti saussuriani a Lipsia e a Berlino", na revista Cahiers Ferdinand de Saussure, Livraria Droz.

5 Por "caso eventual" Saussure se refere à possibilidade de ser naturalizada a opinião de alguns sobre a hipótese de ele ter plagiado, no Mémoire, uma informação cuja origem era a reflexão de um dos seus professores.

6 Na língua francesa, o passado condicional pode cumprir esse papel. 
Saussure a usa largamente: "je fus étudiant" (folha 1); "Je vis" (folha 6); "J'entrai" (folha 7); "je perdis" (folha 9); "lorsque je fis" (folha 15). É o passado simples, tempo que a sua lingua particularmente lhe outorga para designar algo que é passado e acabado no passado, a forma preferida por ele. Atualmente, ela é menos usada, a não ser em situações protocolares, e deixa à forma composta do passado espaço para ampla utilização em língua francesa. É nessa tensão, entre algumas formas nas quais o passado pode se reapresentar, que o genebrino escreve um texto com a proposta de recolocar, a partir das suas lembranças, os fatos que foram decisivos na sua formação e enviar ao seu colega.

A horizontalidade da relação entre Saussure e seu interlocutor, Streitberg, pode ter tido influência no tipo de lembranças trazidas por Saussure no Souvenirs, bem como a forma da escrita desse manuscrito. Note-se que ele retoma lembranças pessoais e particulares, trazidas da sua vivência em família, e não hesita em avaliar seus primeiros interesses pelas questões linguísticas como "admiração infantil" ou "entusiasmo ingênuo". Uma confissão assim, tão desprovida de reservas, parece influenciada pelo tipo de relação que ele depositava no seu interlocutor e nos favorece muito a refletir sobre a formação do linguista.

É assim que, em seguida, ele privilegiará duas figuras do seu entorno familiar com as quais conviveu no periodo da sua infância: o vizinho da casa de campo da família e o avô materno. Os dois surpreendem como grandes influenciadores do linguista que ele se tornou e ainda mais porque a experiência que cada um desses traz é de frustração.

O escrito sobre um sistema geral da linguagem que ele enviou ao "venerável Adolphe Pictet" (folha 5) foi devolvido com palavras de incentivo para seguir em outra direção. As experiências com o avô passavam pela sua biblioteca, suas atividades de pesquisas etimológicas amadoras e, mais especialmente, pela sua busca de um princípio matemático de construção de iates que, por fim, naufragavam. Saussure conta isso com grande admiração pelo espírito de pesquisa do avô, "sem métodos, mas cheio de ideias". É também com admiração que ele lembra do livro de Pictet: "eu não tenho lembranças mais verdadeiras de fruição linguística do que aquelas que me vêm ainda por lufadas dessa leitura da infância" (SAUSSURE, 1903, folha 5), o livro que lhe inspirou o seu primeiro texto de reflexões linguísticas.

Saussure evoca lembranças de infância que podem ser ligadas às atividades profissionais que desenvolveu ao longo da sua vida e também relacionadas à maneira como o genebrino se dedicou a elas. A linguagem manteve-se como seu tema único de ocupação durante toda a sua vida e a pesquisa foi o método do qual ele nunca se desviou no seu trabalho. É evidente que a relação de causa e efeito aqui é pressentida no texto do linguista, mas também pode ser o contrário, ou seja, o genebrino pode evocar essas lembranças a partir da atividade que desenvolve à época em que escreve, dilema que reconhecemos como justo e merecedor de discussões, mas que não se constitui como cerne deste artigo. Por ora, deixemos assinalado apenas o fato de que Saussure encontra elementos para amparar a sua formação em algumas lembranças da infância.

\section{A CUMPLICIDADE TEÓRICA}

Embora essa horizontalidade na relação entre Saussure e Streitberg possa ter evocado lembranças da infância no genebrino, cuja objetividade, em função 
do tema do relato, fosse pouco efetiva, a relação entre ambos os linguistas era diretamente ligada ao tema específico do manuscrito, o Mémoire, o que nos leva a destacar um segundo aspecto da formação do linguista neste manuscrito. $\mathrm{Na}$ primeira folha do Souvenirs, ele nos trará o aspecto que o leva a escrever esse arrazoado sobre a sua formação.

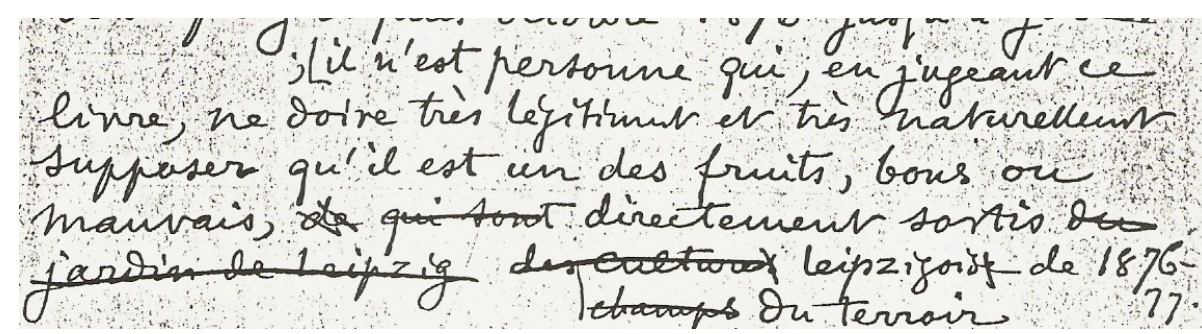

não há quem, ao julgar esse livro, não deva muito legitimamente e naturalmente supor que ele é um dos frutos, bons ou ruins, de que são diretamente saídos dojardim de Leipzig tas eutturas tos eampos leipzigoa do terreno de 1876-77 (folha 1).

Ou seja, Saussure não escreverá simplesmente sobre o Mémoire, mas sim sobre a sua origem intelectual. Por isso ele inicia a primeira folha do relato apresentando a universidade alemã de Leipzig e as excelentes condições de produção desse trabalho na época, em seguida apresenta o próprio Mémoire, colocando a questão teórica que sustenta o mesmo e então finaliza essa folha do caderno, entre rasuras, indicando uma dúvida sobre tal origem.

O lugar que Streitberg ocupa enquanto destinatário do relato, seu primeiro leitor, e que opera nessa narrativa como um interlocutor, acaba também funcionando como um elo entre Saussure e o seu local de formação, bem como um elo com o tema em disputa por autoria. O linguista alemão estudou nos mesmos lugares que o suiço e conhece bem o tema do Mémoire, o que permite uma certa cumplicidade teórica que a partilha constante de cartas atesta.

Essa relação, portanto, permitiu a Saussure um certo lugar de escrita no relato que envia ao linguista alemão. Ele pode ir além das lembranças de infância, sentiu-se à vontade para evocá-las e passar a questões mais teóricas que foram vivenciadas enquanto jovem rapaz e depois na academia. Ele conta que, em 1872, aos 15 anos, teve um ano "perdido", "inútil" na escola para a qual foi enviado, entretanto, o período de tédio no qual nada lhe interessava construiu um vazio suficiente para aí algo se destacar, nas suas palavras:

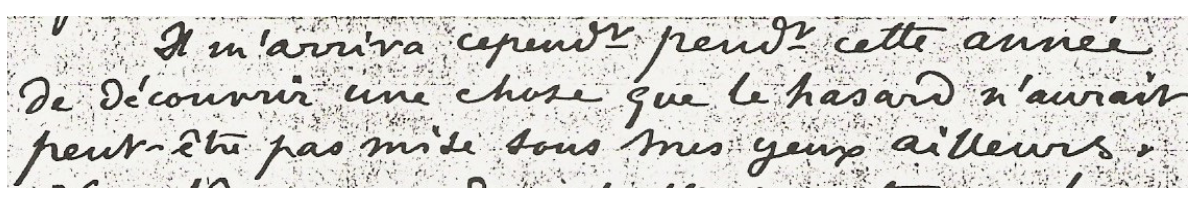

Aconteceu-me, contudo, durante este ano, descobrir algo que o acaso talvez não pudesse ter colocado diante dos meus olhos alhures (folha 7).

Nesse momento, ele recupera a ocasião em que se deu o encontro com o texto de Heródoto, o pai da História, no qual ele percebe uma regularidade na mudança linguística. Joseph vem em nosso auxílio trazendo algumas informações que 
podem ser úteis para que o viajante brasileiro do século XXI possa entender, minimamente, o adolescente suíço do século XIX:

Os alunos de então eram rotineiramente ensinados o dialeto ático, o de Platão e Aristóteles e os outros grandes pensadores de Atenas, antes de passarem a textos de autores de outras regiões da Grécia e de suas colônias asiáticas, onde as formas são diferentes. Saussure foi exposto inicialmente, conforme ele lembra mais tarde, ao texto do historiador Heródoto, escrito no dialeto jônico da costa sudoeste do que hoje é a Turquia (JOSEPH, 2012, p. 132).

Nesse contato, Saussure observa um aspecto do funcionamento da lingua grega, mas o adolescente não demora a descobrir em outras gramáticas do grego notas semelhantes. A sua hipótese não era tão nova. Entretanto, embora conhecido, esse funcionamento da língua grega estava envolvido por uma polêmica, como observa Joseph:

Embora seja verdade que os livros de grego já tinham dito há décadas que o $\mathbf{n}$ se tornou um líquido, houve um período em que o reforço da prática etimológica fez com que dizer que um determinado som "alterado para" outro som, fosse metodologicamente inaceitável, especialmente um som que pertence a uma categoria diferente (JOSEPH, 2012, p. 36).

Assim, embora o rapaz tivesse sido atraído para um fenômeno linguístico que lhe parecia surpreendente e sentido como se tivesse descoberto algo, pôde verificar em seguida que não era algo ignorado na literatura, antes parecia algo bastante conhecido. Contudo, a polêmica teórica supracitada o colocava sob um véu. Disso Saussure não teve consciência naquele momento.

Essa hipótese, ao que parece, lhe sugeriu desdobramentos teóricos. Quatro anos depois ele já estava em Leipzig dando início a sua formação ordinária de linguista. Conforme relato que trazemos para este artigo e várias cartas desse período, Saussure não se sentia à vontade na cidade, na universidade, entre seus colegas ou seus professores, não era muito assíduo às aulas e não via a hora de finalizar a estadia na universidade alemã. Por outro lado, dedicava-se enormemente à escrita do Mémoire. Será que ele "estava destinado a aprender a sua própria sabedoria separado dos outros, ou a aprender sozinho a sabedoria dos outros vagando, ele, por entre as ciladas do mundo" (JOYCE, 1984 [1914], p. 165), como o jovem Dédalus no romance de Joyce?

O fato é que o Mémoire se faz nessas circunstâncias peculiares e nessa obra, que foi por um lado aclamada e por outro ignorada, lê-se a mesma hipótese que Saussure traz desde a leitura de Heródoto e que agora se espraia para outras linguas observadas, traduzindo-se, aqui de forma muito resumida, no que foi chamado de vocalização da nasal. O Souvenirs, portanto, tem este argumento central: situar a origem do Mémoire em uma experiência mais longinqua do que aquela vivida em Leipzig, lugar onde alguns supõem sua procedência: 


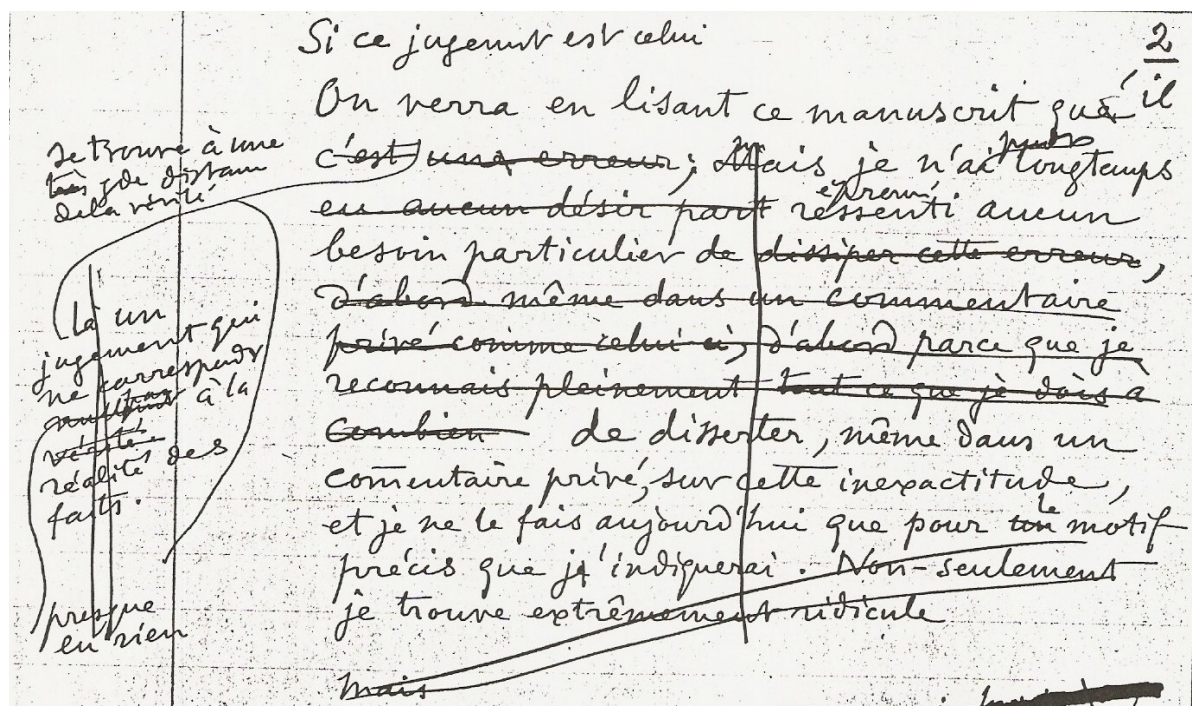

Se o julgamento é este

Ao ler este manuscrito veremos que ele é se encontra a uma distância muttito grande da verdade este

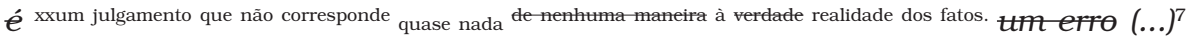
(folha 2).

A base desse fragmento muito rasurado do seu relato é algo como "lendo esse manuscrito não se pode julgar que o Mémoire saiu de Leipzig”. As rasuras e incisos buscam modalizar uma afirmação assim tão forte e que o manuscrito como um todo não desmente. Mas o que isso nos traz sobre a formação do linguista? Talvez seja uma aposta na qual se valorize a relação do linguista com as línguas e os efeitos que dali advêm. Ou seja, a prioridade da experiência de menino com o texto em grego lhe possibilitou uma hipótese.

O fato de que determinada hipótese já tenha sido aventada, ou não se sustente teoricamente, pode não ser o seu fim, mas tão somente um indicio de que esse aspecto observado na língua não sustentava uma hipótese propriamente, mas talvez parte dela. Foi o que se revelou no seu Mémoire. Percorrer a língua e depois a linguística é o que se recolhe aqui. No entanto, como se vê no próprio Mémoire e na leitura que se faz dele, esse caminho realizado pelo genebrino é apagado.

\section{CONCLUSÃo}

O fantástico manuscrito Souvenirs é trabalhado neste modesto artigo de forma muito abreviada. Certamente um trabalho de maior monta acerca desse importante documento ainda é esperado.

Embora o manuscrito se pareça com um manifesto dirigido a um público maior, ele é inspirado por Streitberg, o qual seria o depositário do mesmo - o

7 Em função do inciso, à esquerda no fragmento do manuscrito, reproduzimos mais do que importa à nossa discussão no momento. Contudo, optamos por transcrever e traduzir apenas a afirmação com a qual trabalharemos neste artigo. Além disso, chamamos a atenção para o fato de que o lugar dos incisos nem sempre é claro neste fragmento e as rasuras incidem tanto na horizontal quanto na vertical, o que dificulta ainda mais a compreensão e transcrição do texto. Optamos então por não reproduzir, na transcrição, a rasura vertical pela dificuldade técnica. 
que, de fato, nunca aconteceu, pois esse manuscrito permaneceu na casa de Saussure mesmo várias décadas após a sua morte.

Apesar de não ter chegado ao seu destinatário, é possivel considerar que o próprio linguista alemão esteve no horizonte de Saussure enquanto escrevia o Souvenirs. Dessa forma, destacamos, neste artigo, duas características apontadas por Saussure na sua formação e as alinhamos com a especificidade da interlocução. Em primeiro lugar, procuramos evidenciar a horizontalidade da relação entre os dois, em segundo, a cumplicidade teórica explicitada pelos estudos formais, o interesse compartilhado e o conhecimento de detalhes do tema do manuscrito, como atesta a correspondência entre eles. Considerando a especificidade dessa interlocução, sublinhamos aspectos da infância e da juventude do genebrino como possibilidades de formação daquele linguista, mas que nos levam a pensar na formação do linguista de um modo geral.

A nossa leitura, portanto, permite destacar que Saussure: 1. encontra elementos para amparar a sua formação de linguista em algumas experiências da infância das quais tem lembrança e 2. recolhe, de uma experiência de leitura na adolescência, algo que lhe acompanhou e frutificou em um trabalho na sua instrução formal, de linguista especificamente. Em relação à infância, ninguém mais que Freud pode, neste momento da nossa empreitada, nos franquear uma possibilidade de entender a pertinência dessas observações de Saussure:

Mesmo que a psicanálise não esclareça o poder artístico de Leonardo, pelo menos torna, para nós, mais compreensíveis suas manifestações e suas limitações. Parece, em todo caso, que somente um homem que tivesse passado pelas experiências infantis de Leonardo poderia ter pintado a Mona Lisa e a Sant'Ana, ter acarretado um destino tão melancólico para suas obras e ter embarcado numa carreira tão extraordinária de cientista [...] (FREUD, 1994 [1910], p. 209).

É isso que Saussure traz no Souvenirs, um traço da sua existência que torna mais compreensivel para ele as suas manifestações e limitações e, consequentemente, mais acessivel para nós a forma como um falante pode se tornar linguista.

Saussure coloca o seu foco na sua relação com o grego, especialmente na adolescência. É preciso destacar essa importância que ele dedica àquele contato com o texto do Heródoto. Essa experiência digna de ser recordada 30 anos depois, cuja impressão atravessou os tempos seguintes da sua formação e se impôs à instrução formal em linguística. Milner, em O amor da língua, nos permite pensar esse acontecimento. Ele finaliza o capítulo "Do linguista" com a seguinte provocação:

Mas quem pode ignorar que, a todo instante, do próprio seio do objeto definido, o espectro da verdade pode se erguer, testemunha da incompletude e do dilaceramento dos quais dependem tanto o gestuário das teorias quanto a permanência das qualificações acadêmicas? (MILNER, 2012 [1987], p. 118).

Após ele afirmar durante todo o capítulo o pertencimento da Linguística a um domínio do discurso acadêmico regrado por rituais institucionais, aos quais o linguista se vê na ânsia e no dever de curvar-se, ele finaliza lembrando que o próprio objeto (a língua) concernente à área e ao sujeito é que pode, por fim, mostrar o vazio, o espaço de criação para além do ritual.

Assim, o autorretrato de Saussure quando jovem, um relato muito particular sobre a sua formação e que nos remeteu ao bildungsroman, nos permite refletir 
sobre alguns aspectos muito pouco tratados da formação do linguista e que estão para além da sua instrução formal, contudo, não necessariamente dela isolados.

\section{Portrait OF THE LINGUist WHEN YOUNG}

Abstract: This article reflects on the formation of the linguist, based on Saussure's observations presented in his 1903 manuscript known as Souvenirs. From his childhood and youth memories, the Genevan linguist takes up significant elements of his education. In this article, we prioritize some aspects of these memories that were addressed to a colleague, the German linguist Wilhelm Streitberg, and we discuss the status of these aspects in the formation of the linguist.

Keywords: Ferdinand de Saussure. Linguist. Manuscript. Memories. Linguistics.

\section{REFERÊNCLAS}

AUBERT, J. Um retrato do artista quando jovem: uma introdução. Tradução Ana Lucia Teixeira Ribeiro. In: Retratura de Joyce: uma perspectiva lacaniana. Revista da Escola Letra Freudiana, Rio de Janeiro, ano XII, n. 13, p. 40-51, 1993. BÉGUELIN, M. J. La Méthode comparative et l'enseignement du Mémoire. In: BOUQUET, S. Saussure. Paris: Editions de l'Herne, 2003.

FREUD, S. Leonardo da Vinci e uma lembrança de sua infância. Rio de Janeiro: Imago, 1994 [1910].

GODEL, R. Souvenirs de F. de Saussure concernante sa jeunesse et ses études. Cahiers Ferdinand de Saussure - CFS, Genève, v. 17, p. 12-25, 1960.

JOSEPH, J. E. Saussure. Oxford: Oxford University Press, 2012.

JOYCE, J. Retrato do artista quando jovem. Tradução José Geraldo Vieira. Rio de Janeiro: Civilização Brasileira, 1984 [1914].

MILNER, J. C. O amor da língua. Tradução Paulo Sérgio de Souza Júnior. Campinas: Editora da Unicamp, 2012 [1987].

NABUCO, J. Minha formação. São Paulo: Editora 34, 2012.

SAUSSURE, F. Récit Autobiographique de sa jeunesse et de ses études: 3957-1. Bibliotèque de Genève, 1903.

SILVEIRA, E.; SÁ, I.; FERNANDES, C. A. Problemas da autoria em Ferdinand de Saussure: do percurso intelectual à constituição da obra. Leitura, Maceió, v. 1, n. 62, p. 235-254, jan./jun. 2019. Disponivel em: http://www.seer.ufal. br/index.php/revistaleitura/article/view/5080.\%20Revista\%20Leitura,\%20v. \%201,\%20p.\%20235-254,\%202019. Acesso em: 5 jul. 2020.

VILLANI, P. Documenti saussuriani a Lipsia e a Berlino. Cahiers Ferdinand de Saussure, Géneve, v. 44, p. 3-33, 1990. 